Original Article

\title{
Comparison of energy expenditure during the Y-balance test in older adults with different visual acuities
}

\author{
Sun-Shil Shin, PT, MS ${ }^{1)}$, Duk-Hyun An, PT, $\mathrm{PhD}^{2)^{*}}$ \\ 1) Department of Rehabilitation Science, The Graduate School, Inje University, Republic of Korea \\ 2) Department of Physical Therapy, College of Biomedical Science and Engineering, Inje University: \\ 197 Inje-ro, Gimhae-si, Gyeongsangnam-do 621-749, Republic of Korea
}

\begin{abstract}
Purpose] This study compared the energy expenditure during the Y-balance test (YBT) between elderly women with good binocular visual acuity (BVA) and those with poor BVA. [Subjects] Twenty-one elderly women who could walk independently were recruited from a community dwelling. Eleven participants had a BVA equal to or less than 0.4 logarithm of the minimum angle of resolution $(\log M A R)$, and the other 10 participants had a BVA equal to or better than $0.3 \log$ MAR. [Methods] The participants had an accelerometer attached over the L3 spinous process for measurement of energy expenditure and performed the YBT in the anterior, posteromedial, and posterolateral directions. [Results] The normalized reach distance in the good BVA group during the YBT in three directions and composite reach distance were significantly longer compared with the values in the poor BVA group. The energy expenditure in the good BVA group during the YBT in the three directions was significantly reduced compared with the values in the poor BVA group. [Conclusion] We suggest that visual acuity in the elderly influences dynamic balance and energy expenditure. Elderly subjects with poor BVA showed poor dynamic balance control and an inefficient biomechanical cost strategy compared to subjects with good BVA.
\end{abstract}

Key words: Energy expenditure, Visual acuity, Y-balance test

(This article was submitted Aug. 26, 2014, and was accepted Oct. 15, 2014)

\section{INTRODUCTION}

Many older adults have substantial vision problems such as cataracts, glaucoma, and macular degeneration, which are the leading causes of reduced visual acuity ${ }^{1}$. Poor vision is one of the most important risk factors associated with falls among older people ${ }^{2}$. Vision plays a key role in maintaining balance by providing information about the environment and constant information to the central nervous system about body orientation in space and relative to other body parts ${ }^{3)}$.

Achieving effectively maintained balance during functional dynamic balance tasks requires energy efficiency to minimize fatigue, which is associated with postural control deficits, and stability to prevent falling or injury ${ }^{4}$. Among the clinical balance tests, the single-limb stand (SLS) is a commonly used clinical tool for assessing postural stability in the elderly and individuals with various balance disorders. The Y-balance test (YBT), which was developed by clinical applications of the Star Excursion Balance Test, involves maintaining a SLS while reaching as far as possible with the

*Corresponding author. Duk-Hyun An (E-mail: dhahn670208@gmail.com)

C2015 The Society of Physical Therapy Science. Published by IPEC Inc. This is an open-access article distributed under the terms of the Creative Commons Attribution Non-Commercial No Derivatives (by-ncnd) License $<$ http://creativecommons.org/licenses/by-nc-nd/3.0/>. other leg. As a dynamic SLS balance test, the YBT has been used to prospectively identify individuals who have chronic ankle instability and greater risk of lower extremity injury in sports and as a post-rehabilitation test ${ }^{5}$. . Recently, the test has been used as a screening tool for elderly participation ${ }^{6}$. However, no studies have investigated energy expenditure during the dynamic single-limb balance test in older adults with different visual acuities. Therefore, this study compared energy expenditure in the YBT, the functional dynamic single-limb balance test, in elderly people with good and poor binocular visual acuity (BVA).

\section{SUBJECTS AND METHODS}

A total of 21 elderly females from community housing were enrolled in the present study. Visual acuity was measured by use of a, Jin's vision test chart (JV Institute, Seoul, South Korea). Each participant's BVA was evaluated with and without their own spectacles for classification into two groups: poor BVA (corrected BVA $\leq 0.4$ logarithm of the minimum angle of resolution [logMAR]) and good BVA

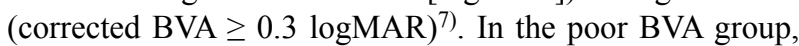
the participants' average age (mean $\pm \mathrm{SD}$ ), height, and weight were $78.55 \pm 5.24$ years, $148.86 \pm 2.77 \mathrm{~cm}$, and $49.46 \pm 6.05 \mathrm{~kg}$, respectively; they had a left side VA and right side VA of $0.53 \pm 0.15 \log \mathrm{MAR}$ and $0.54 \pm 0.16 \log \mathrm{MAR}$, respectively. In the good BVA group, the participants' average age, height, and weight were $76.40 \pm 6.13$ years, $147.00 \pm 4.00 \mathrm{~cm}$, and 
$48.99 \pm 4.91 \mathrm{~kg}$, respectively; they had a left side VA and right side VA of $0.23 \pm 0.07 \log$ MAR and $0.23 \pm 0.09 \log M A R$, respectively. All participants could walk independently without an assistive device and scored greater than 24 points on the Korean Version of the Mini-Mental State Examination. They had no past or present neurological disorder, no musculoskeletal disease that could interfere with daily activities, and no significant auditory impairments, and they were not taking drugs that could have influenced the results of this study. Ethical approval was obtained from the Inje University Faculty of Health Science Human Ethics Committee, and all subjects signed an informed consent form prior to their participation.

A triaxial accelerometer (Fit. Life, Suwon, South Korea) was used to measure energy expenditure during the YBT. We measured the raw data using the $\mathrm{x}, \mathrm{y}$, and $\mathrm{z}$ variables of acceleration reformed as acceleration due to activity by removing gravitational acceleration. Moreover, we calibrated the single vector magnitude (SVM) by summing the acceleration of the three axes ${ }^{8)}$ :

$$
\mathrm{SVM}=\sqrt{\mathrm{Ax}^{2}+\mathrm{Ay}^{2}+\mathrm{Az}}
$$

In the present study, a range of $\pm 2 \mathrm{G}$ was selected. Data were collected at a sampling rate of $32 \mathrm{~Hz}$.

Before the task, the participant's dominant leg was determined by kicking a soccer ball. For normalization, the lower limb lengths of all participants were measured in supine position from the anterior superior iliac spine to ipsilateral medial malleolus using a cloth tape measure. Reach distance was normalized to limb length, and the maximum reach distance was expressed as a percentage of limb length (\%MAXD). The normalized value was calculated as reach distance divided by limb length and then multiplied by 100 . Composite reach distance was the sum of the three reach directions divided by 3 times the limb length, which was then multiplied by 100 . The investigator explained the testing method before the participants performed the YBT. The accelerometer was fixed with double-sided adhesive tape over the L3 spinous process ${ }^{9}$.

For the test, the participants stood with one foot on the center footplate from the YBT Kit ${ }^{\mathrm{TM}}$ (Move2Perform, Evansville, IN, USA) at the starting line and their hands on their pelvis. They were asked to push the reach-indicator block with the free limb in the anterior (A), posterior medial (PM), and posterior lateral (PL) directions in relation to the stance foot on the central footplate. The testing order was trial standing on the right foot reaching in the A direction (right A reach) followed by trial standing on the left foot reaching in the A direction. This procedure was repeated for the PM and the PL reaching directions ${ }^{10)}$. The participants completed four practice trials in each direction on each leg. After the test trials were completed, each participant was given a 2-minute rest period and then conducted three test trials in each direction ${ }^{11)}$. All testing and practice trials were carried out barefoot. A trial was classified as invalid if the participant did not return to the starting position, placed the reach foot on the ground on either side of the line or tube, raised or moved the stance foot during the test, or kicked the plate with the reach foot to gain more distance. If an invalid trial occurred, the data were discarded, and the participant repeated the trial.

Statistical analysis was performed using the SPSS software (version 18.0 for Windows, SPSS Inc., Chicago, IL, USA). A paired t-test was used to examine differences between right and left limb reach distances. As no differences were found, for the data analysis, we used the dominant limb distance in each direction (right side). The differences in reach distance and energy expenditure were analyzed using the independent t-test for comparisons between groups. Effect sizes (Cohen's $d$ ) for test differences were calculated by determining the difference between the poor BVA and good BVA group mean values and dividing by the pooled standard deviation ${ }^{12)}$. Significance was accepted for values of $\mathrm{p}<0.05$.

\section{RESULTS}

The normalized reach distance (\%MAXD) in the good BVA group (A, 60.8 \pm 4.3 ; PM, 94.3 $\pm 6.1 ; \mathrm{PL}, 88.9 \pm 7.8$ ) during the YBT in the three directions and composite reach $(81.3 \pm 4.8)$ were significantly longer $(p<0.05)$ compared with the values in the poor BVA group (A, 55.6 \pm 5.9 ; PM, 84.2 \pm 9.9 ; PL, 81.7 \pm 5.4 ; composite, $73.8 \pm 6.2$ ). The energy expenditure $\left(\mathrm{cm} / \mathrm{s}^{2}\right)$ in the good BVA group during the YBT in the three directions (A, 413.8 $\pm 145.2 ; \mathrm{PM}, 490.0 \pm 189.4$; PL, $585.8 \pm 209.7)$ was significantly reduced $(\mathrm{p}<0.05)$ compared with the values in the poor BVA group (A, 697.4 \pm 231.6 ; PM, 698.8 \pm 227.3 ; PL, 791.6 \pm 182.7 ). The effect size value of the reach distance and energy expenditure showed that the results were large for the A ( -1.064 and 1.525), PM ( -1.268 and 1.044), PL directions ( -1.187 and 1.104) and composite reach $(-1.412)$ in terms of the differences between the good and poor BVA groups.

\section{DISCUSSION}

This study was designed to compare energy expenditure and reach distance during the YBT in elderly women with good BVA and poor BVA. It showed that normalized reach distances in the A, PM, and PL directions and the composite reach of the good BVA group were significantly greater compared with the values in the poor BVA group. The reach distance during the YBT reflected the degree of dynamic balance control. A longer reach distance represented greater dynamic postural control. Thus, our findings suggest that visual acuity affects the functional dynamic SLS in the A, PM, and PL directions. Moreover, older adults with poor BVA are more balance challenged compared with those with good BVA.

In the A reach direction, participants received visual feedback during the YBT. Wang et al. ${ }^{13)}$ showed that reduction of the stability boundary of the multi-joint coordination patterns in maintaining the SLS in the absence of vision could lead to increased rotation of segments around the center of mass. Hallemans et al. ${ }^{14)}$ reported that no vision conditions limited movements of the hip and ankle in the sagittal plane compared with a full vision condition. Although, visual awareness is reduced in the PM and PL directions compared with the A direction, participants with good BVA have a 
longer reach compared with those with poor BVA. When one sense diminishes, it is common to find a greater dependence on other sensory cues to preserve balance ${ }^{15)}$. However, Hazime et al. ${ }^{16)}$ reported that vision had a key role in the SLS, requiring greater balance ability, whereas perturbation in proprioception showed effects only in the double- limb stance. The stance platform of the YBT Kit ${ }^{\mathrm{TM}}$ is elevated 1 inch, and its width is 5.2 inches; thus, maintaining balance in the dynamic SLS on the balance platform of the YBT Kit ${ }^{\mathrm{TM}}$ is greater challenge than doing so on the ground in elderly subjects. The results show that elderly people with good and poor BVA rely more on visual input than other sensory inputs for postural control. In addition, in this study, the energy expenditure during the YBT in three directions in the poor BVA group was significantly increased compared with the values in the good BVA group. An accelerometer was used as an objective tool for assessing physical activity level related to energy expenditure. Accelerometry has been shown to have intra-rater reliabilities $(0.925-0.994)$ and correlation with scores on the commonly used physical activity questionnaire $\left.(\mathrm{r}=0.830)^{17}\right)$. Our results imply that the velocity of trunk segment motion frequently changes and fluctuates, and that ineffective biomechanical cost strategies in terms of energy efficiency are performed. Individuals with poor BVA may habituated to discomforts visual acuity and rely more on ankle proprioception to control their posture during quiet standing. When balance challenged with conditions such as the SLS, vision play a major role compared with in a normal standing position. Thus we surmise that these individuals compensate with trunk rotation during YBT in order to maintain postural stability ${ }^{16,18)}$. Hence, participants with good BVA have a longer reach in the YBT compared with those with poor BVA.

This study had some limitations. First, it only measured reaching distances and energy expenditure. Measurements of muscle activation and range of motion in the trunk and lower extremities were not taken. Thus, we could not explain the connection between energy expenditure and fatigue or trunk lean during the YBT. Second, the valid of the triaxial accelerometry in measurement of energy expenditure during a short period of activity has not been verified. In addition, the sample size was small, so caution should be used when generalizing the results. Further studies should investigate kinematic and kinetic data, as well as the correlation of the YBT with gait parameters in elderly subjects with poor BVA.

\section{REFERENCES}

1) Kovács E, Tóth K, Dénes L, et al.: Effects of exercise programs on balance in older women with age-related visual problems: a pilot study. Arch Gerontol Geriatr, 2012, 55: 446-452. [Medline] [CrossRef]

2) Patino CM, McKean-Cowdin R, Azen SP, et al. Los Angeles Latino Eye Study Group: Central and peripheral visual impairment and the risk of falls and falls with injury. Ophthalmology, 2010, 117: 199-206, el. [Medline] [CrossRef]

3) Lord SR: Visual risk factors for falls in older people. Age Ageing, 2006, 35: ii42-ii45. [Medline]

4) Reimer RC 3rd, Wikstrom EA: Functional fatigue of the hip and ankle musculature cause similar alterations in single leg stance postural control. J Sci Med Sport, 2010, 13: 161-166. [Medline] [CrossRef]

5) Gribble PA, Hertel J, Plisky P: Using the Star Excursion Balance Test to assess dynamic postural-control deficits and outcomes in lower extremity injury: a literature and systematic review. J Athl Train, 2012, 47: 339-357. [Medline]

6) Lee DK, Kim GM, Ha SM, et al.: Correlation of the Y-balance test with lower-limb strength of adult women. J Phys Ther Sci, 2014, 26: 641-643. [Medline] [CrossRef]

7) Bhavsar KV, Freund KB: Retention of good visual acuity in eyes with neovascular age-related macular degeneration and chronic refractory subfoveal subretinal fluid. Saudi J Ophthalmol, 2014, 28: 129-133. [Medline] [CrossRef]

8) Kim Y, Jung YS, Park RW, et al.: Different location of triaxial accelerometer and different energy expenditures. Yonsei Med J, 2014, 55: 1145-1151. [Medline] [CrossRef]

9) Tucker MG, Kavanagh JJ, Barrett RS, et al.: Age-related differences in postural reaction time and coordination during voluntary sway movements. Hum Mov Sci, 2008, 27: 728-737. [Medline] [CrossRef]

10) Plisky PJ, Rauh MJ, Kaminski TW, et al.: Star Excursion Balance Test as a predictor of lower extremity injury in high school basketball players. J Orthop Sports Phys Ther, 2006, 36: 911-919. [Medline] [CrossRef]

11) Coughlan GF, Fullam K, Delahunt E, et al.: A comparison between performance on selected directions of the star excursion balance test and the $Y$ balance test. J Ath1 Train, 2012, 47: 366-371. [Medline]

12) Fetters L, Tilson J: Evidence-based Physical Therapy. Philadelphia: F.A. Davis, 2012.

13) Wang Z, Molenaar PC, Challis JH, et al.: Visual information and multijoint coordination patterns in one-leg stance. Gait Posture, 2014, 39: 909 914. [Medline] [CrossRef]

14) Hallemans A, Ortibus E, Meire F, et al.: Low vision affects dynamic stability of gait. Gait Posture, 2010, 32: 547-551. [Medline] [CrossRef]

15) Shumway-Cook A, Woollacott M: Motor Control: Translating Research into Clinical Practice, 4th ed. Philadelphia: Lippincott Williams \& Wilkins, 2010.

16) Hazime FA, Allard P, Ide MR, et al.: Postural control under visual and proprioceptive perturbations during double and single limb stances: insights for balance training. J Bodyw Mov Ther, 2012, 16: 224-229. [Medline] [CrossRef]

17) Gao KL, Tsang WW: Use of accelerometry to quantify the physical activity level of the elderly. Hong Kong Physiother J, 2008, 26: 18-23. [CrossRef]

18) Ham YW, Kim DM, Baek JY, et al.: Kinematic analyses of trunk stability in one leg standing for individuals with recurrent low back pain. J Electromyogr Kinesiol, 2010, 20: 1134-1140. [Medline] [CrossRef] 